\title{
Extending boundaries in minimally invasive procedures with simultaneous bilateral video endoscopic inguinal lymphadenectomy (veil) for penile cancer: initial Denver health medical center and $A B C$ school of medicine experience and surgical considerations
}

Alexandre Pompeo, Marcos Tobias-Machado,Wilson R. Molina, Jarkes Lucio II, David Sehrt, Antonio Carlos Lima Pompeo, Fernando J. Kim

Division of Urology, Department of Surgery, Denver Health Medical Center and University of Colorado Health Sciences Center (AP, WRM, DS, FJK), Denver, Colorado, USA; Division of Urology, ABC Medical School (MTM, JLII, ACLP), Sao Paulo, Brazil and Tony Grampsas Cancer Institute (FJK), Denver, Colorado, USA

\section{ABSTRACT}

Purpose: To report the surgical technique, procedural outcomes, and feasibility of simultaneous bilateral Video Endoscopic Inguinal Lymphadenectomy (VEIL) in the management of patients with indication for inguinal lymphadenectomy.

Surgical Technique: VEIL was applied in all patients using the oncological landmarks (the adductor longus muscle medially, the sartorius muscle laterally and the inguinal ligament superiorly). A $1.5 \mathrm{~cm}$ incision was made $2 \mathrm{~cm}$ distally to the lower vertex of the femoral triangle. A second incision was made $2 \mathrm{~cm}$ proximally and $6 \mathrm{~cm}$ medially. Two $10 \mathrm{~mm}$ Hasson trocars were inserted in these incisions and the working space was insufflated with $\mathrm{CO}_{2}$ at 5-15 mmHg. The final trocar was placed $2 \mathrm{~cm}$ proximally and $6 \mathrm{~cm}$ laterally from the first port.

Results: A total of 5 VEIL procedures in 3 patients were performed. Two patients underwent simultaneous bilateral VEIL while another underwent simultaneous bilateral surgery with VEIL on the right and open lymphadenectomy on the left side due to an enlarged node. All laparoscopic procedures were successfully performed without conversion and maintained the oncological templates. One lymphocele occurred in the patient who underwent the open procedure. None of the patients presented with skin necrosis after the procedure. Mean number of nodes retrieved was 6 from each side and 2 patients presented with positive inguinal nodes. After one year of follow-up no recurrences were observed.

Conclusion: Simultaneous lymphadenectomy procedures are feasible. Improvement in operative and anesthesia time could decrease the morbidity associated with inguinal lymphadenectomy while maintaining the oncological principles.

\section{ARTICLE INFO}

\section{Key words:}

Penile Neoplasms; Lymph

Node Excision; Laparoscopy;

Surgical Procedures,

Minimally Invasive; Endoscopy

Int Braz J Urol. 2013; 39: 587-92

Submitted for publication:

December 03, 2012

Accepted after revision:

June 14, 2013

\section{INTRODUCTION}

In patients with penile cancer, lymph node metastasis is the most important factor affecting survival. However, open radical inguinal lymphadenectomy is associated with high morbidity. To reduce morbidity, video endoscopic inguinal 
lymphadenectomy (VEIL) was established as a new approach. However, reducing the field of dissection in the endoscopic method increased the potential for false-negative histopathological results and thus, possibly compromised the oncological effectiveness of the procedure. Although clinical experience is still limited in endoscopic inguinal dissection, there appears to be less morbidity and the early oncologic results are encouraging (1). However, these results are still investigational and require longer follow-up. Currently there are no reports of a simultaneous inguinal lymphadenectomy procedure. This procedure may reduce operative and anesthesia time and further decrease the morbidity of surgery. Our objective is to report the surgical technique, procedural outcomes, and feasibility of simultaneous bilateral lymph node resssection in the management of patients with indication for inguinal lymphadenectomy.

\section{Statistical analysis}

Three patients initially underwent partial penectomy for penile cancer. Due to the high risk of developing inguinal metastasis, lymphadenectomy was further indicated. Two patients underwent simultaneous bilateral VEIL while ano- ther underwent simultaneous bilateral surgery with VEIL on the right and open lypmhadenectomy on the left side due to palpable $3 \mathrm{~cm}$ node.

\section{Patient positioning and trocar placement}

The patient was placed in supine frog leg position. Two surgeons simultaneously performed the procedure from the lateral sides with their respective laparoscopic monitors on the opposite side of the table (Figure-1). A $1.5 \mathrm{~cm}$ incision was made $2 \mathrm{~cm}$ distally to the lower vertex of the femoral triangle. Scissors were employed to develop a plane of dissection deep to Scarpa's fascia. A second incision was made $2 \mathrm{~cm}$ proximally and $6 \mathrm{~cm}$ medially. Two $10 \mathrm{~mm}$ Hasson trocars were inserted in these incisions and the working space was insufflated with $\mathrm{CO}_{2}$ at 5-15 mmHg. The final trocar was placed $2 \mathrm{~cm}$ proximally and $6 \mathrm{~cm}$ laterally from the first port (Figure-2).

\section{Dissection}

Video endoscopic inguinal lymphadenectomy with the same template of open surgery was performed bilaterally simultaneously. The main landmarks - the adductor longus muscle medially, the sartorius muscle laterally and the inguinal ligament superiorly -were well visualized (2). The

Figure 1 - Simultaneous bilateral VEIL.

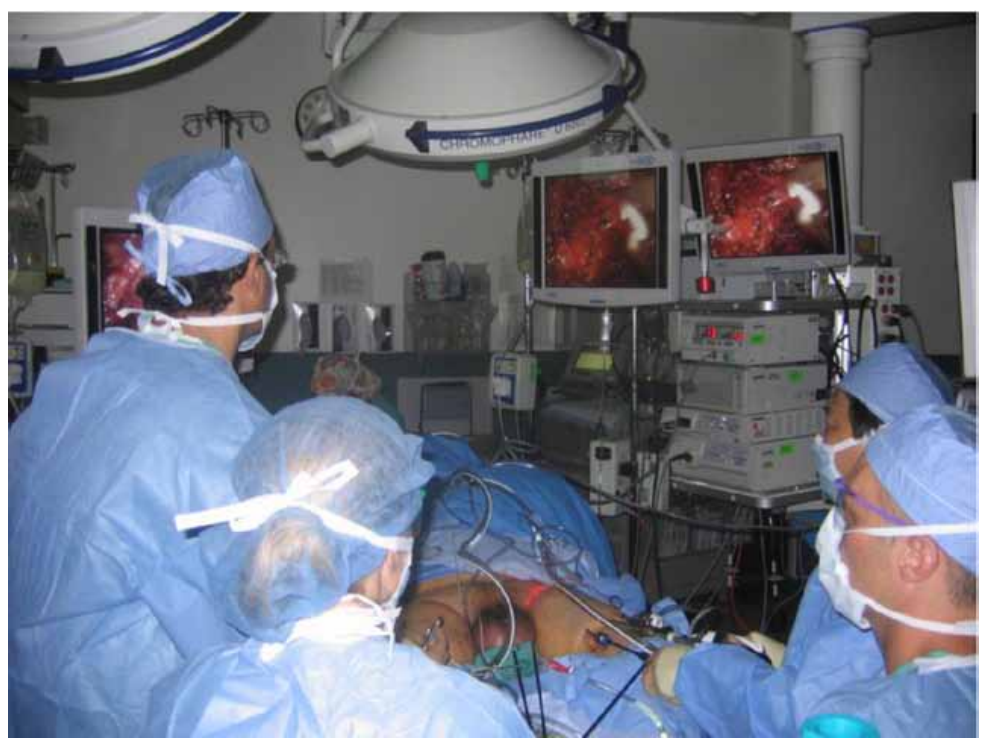


Figure 2 - Final aspect of the trocar incisions and drainage.

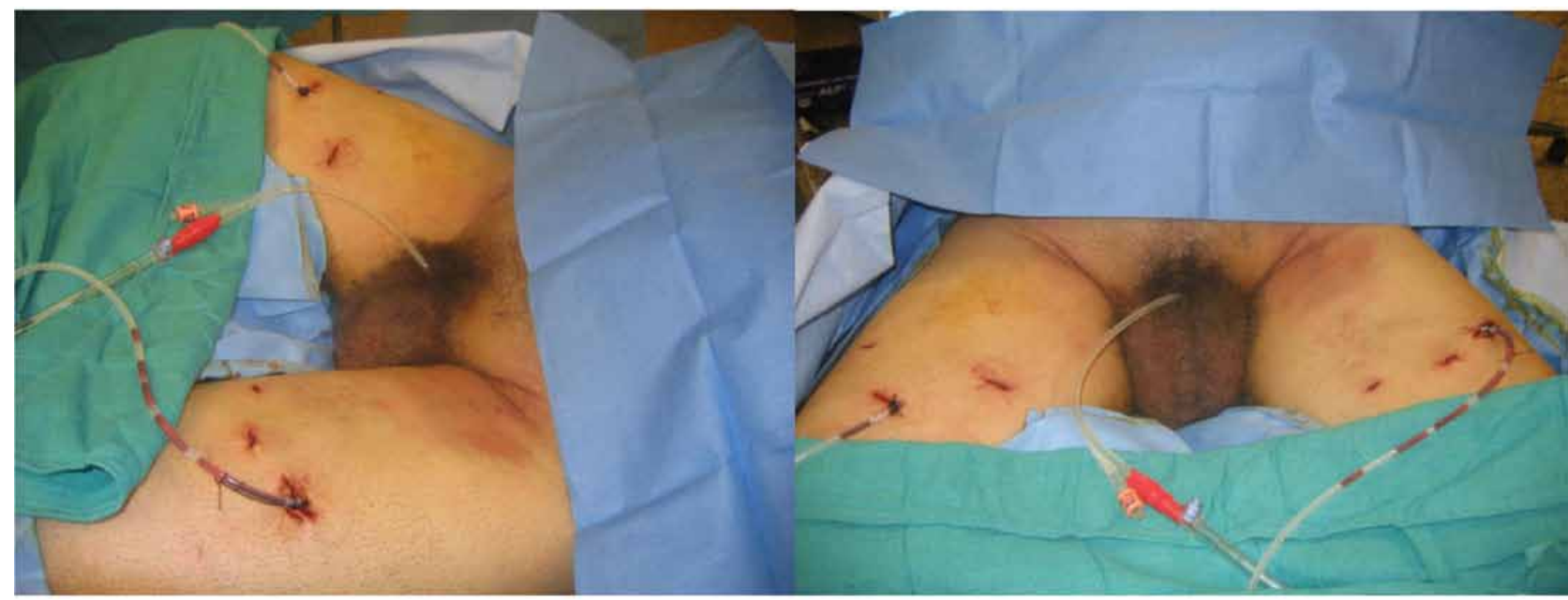

retrograde dissection with minimal use of the ultrasonic scalpel was initiated distally near the vertex of the femoral triangle towards the fossa ovalis. The safena vein was identified, clipped, and divided towards the femoral artery laterally. After the procedure, the skeletonized femoral vessels and the empty femoral channel could be identified, confirming the lymphatic tissue in this region was completely resected.

\section{Specimen retrieval and closure of ports}

The surgical specimen was removed through the first port incision. A suction drain was placed to prevent lymphocele development. Patients were discharged and drains were removed when output was $<50 \mathrm{~mL}$.

\section{COMMENTS}

Cancer of the penis is a rare malignant disease and treatment causes devastating effects on patients' physical and psychological health. The low incidence of this disease in developed countries in contrast with the high incidence in developing countries clearly indicates the disease's association with local economic conditions (3). Brazil has one of the highest incidences of penile cancer in the World. An epidemiological study published by Favorito et al. demonstrated that in some regions of Brazil, this mutilating disease is endemic and directly linked with socio-economic status (4). Despite these factors appropriate management and treatment outcomes in men with squamous cell carcinoma of the penis depends critically on the correct diagnosis, grading, and staging of the malignancy.

The presence and extent of regional lymph nodes are the most important determinants of survival in patients with penile squamous cell carcinoma (5). At initial presentation, clinically palpable inguinal lymph nodes are present in $28 \%-64 \%$ of patients with penile squamous cell carcinoma. In 47\%-85\% of these patients, lymphadenopathy is caused by metastatic invasion while inflammatory reactions account for the remainder (3). In this setting the management of inguinal lymph nodes is important. A prospective study published by Pompeo et al. showed that spread to the right side, left, and bilaterally occurred in 24\%, 30\%, and 46\% of patients, respectively. Therefore, it was proposed that bilateral inguinal lymphadenectomy (ILND) should be the standard in the management for patients who require lymphadenectomy (6).

Although the survival benefits of lymphadenectomy in patients with penile cancer and impalpable lymph nodes have been well demonstrated, elevated morbidity remains an issue for the traditional surgical approach. The risks and complications associated with an open inguinal lymph node dissection include necrotic skin flaps 
and elevated risk of lymphoceles which has driven several investigators to develop techniques for performing a minimally invasive endoscopic inguinal lymph node dissection. The feasibility of endoscopic subcutaneous inguinal lymphadenectomy nowadays is well established and is an option in experienced laparoscopic hands (7). Since the introduction of VEIL by Tobias-Machado in 2006, there has been a surge of interest in this technique (8). Although VEIL surgery is technically demanding primarily because of the small working space, more than 20 centers, including the use of robotic platform, have reported their initial experience with similar technical success and improved morbidity rates (1). Sotelo et al. showed that VEIL carries a lower risk of skin complications compared with an open approach (9). A recent paper comparing open and laparoscopic lymphadenectomy suggested that VEIL may decrease postoperative morbidity without compromising oncological control (3). By performing a simultaneous bilateral procedure, it is thought that the morbidity would be further decreased while maintaining the oncological efficacy of conventional VEIL.

In our study, although there are a small number of patients, we describe the first experience in simultaneous bilateral VEIL. Despite the necessity of two laparoscopic sets, this new approach may decrease the operation room and anesthesiology time without compromising on- cological outcomes. Although this procedure was performed by two different surgeons, there was no clashing between the surgical groups demonstrating the feasibility and some advantages of this method. All VEIL procedures were completed without conversions (Table-1). Operative time ranged from 120-150 min. Patients were discharged at 1-2 days and the drain was removed after 5-10 days during the follow-up clinic visit. Mean number of nodes retrieved was 6 for each side and 2 patients presented with positive inguinal nodes. In a mean follow-up period of 12 months no systemic or local recurrence has been documented. No complications related to VEIL were reported. There was only 1 lymphocele from the bilateral lymphadenectomies that occurred in the open approach with the palpable node. This patient had prolonged drainage and the drain was withdrawn after 1 week. The patient later returned to the hospital 2 weeks postoperative with an inguinal fluid collection treated successfully by simple drainage.

To our knowledge, simultaneous bilateral inguinal lymph node dissection has only been performed in one other institution (10). A minimally invasive approach circumventing the need for thick skin flaps coupled with the simultaneous procedure's improvement in operative and anesthesia time could decrease the morbidity associated with inguinal lymphadenectomy while maintaining oncological principles.

Table1 - Patient's characteristics and outcomes.

\begin{tabular}{|c|c|c|c|c|c|c|c|c|}
\hline $\begin{array}{l}\text { VEIL } \\
\text { Procedures }\end{array}$ & Age & $\begin{array}{c}\mathrm{N} \\
\text { clinical/stage }\end{array}$ & $\begin{array}{c}\text { Risk } \\
\text { Stratification }\end{array}$ & ORT & Complications & Positive Nodes & $\begin{array}{l}\text { Hosp. } \\
\text { Stay (d) }\end{array}$ & $\begin{array}{c}\text { Drain } \\
\text { (d) }\end{array}$ \\
\hline 2 & 73 & N1 & high & $\begin{array}{l}130 \\
\min .\end{array}$ & none & $\begin{array}{c}0 / 3 \text { right } \\
1 / 3 \text { left }\end{array}$ & 2 & 6 \\
\hline 2 & 64 & NO & high & $\begin{array}{l}120 \\
\min .\end{array}$ & none & $\begin{array}{c}\text { 0/6 right } \\
0 / 7 \text { left }\end{array}$ & 1 & 5 \\
\hline $\begin{array}{l}1 \\
{ }^{\star} \text { Open Left }\end{array}$ & 55 & N2 & high & $\begin{array}{l}150 \\
\min .\end{array}$ & $\begin{array}{c}\text { Lymphocele on } \\
\text { the left }\end{array}$ & $\begin{array}{c}\text { 0/8 right } \\
2 / 8 \text { left }\end{array}$ & 2 & 10 \\
\hline
\end{tabular}

ORT = Operation time 


\section{CONFLICT OF INTEREST}

None declared.

\section{REFERENCES}

1. Tobias-Machado M, Tavares A, Silva MN, Molina WR Jr, Forseto $\mathrm{PH}$, Juliano RV, et al.: Can video endoscopic inguinal lymphadenectomy achieve a lower morbidity than open lymph node dissection in penilecancer patients? J Endourol. 2008; 22: 1687-91.

2. Canter DJ, Dobbs RW, Jafri SM, Herrel LA, Ogan K, Delman $K A$, et al.: Functional, oncologic, and technical outcomes after endoscopic groin dissection for penile carcinoma. Can J Urol. 2012; 19: 6395-400.

3. Solsona E, Algaba F, Horenblas S, Pizzocaro G, Windahl T; European Association of Urology: EAU Guidelines on Penile Cancer. Eur Urol. 2004; 46: 1-8.

4. Favorito LA, Nardi AC, Ronalsa M, Zequi SC, Sampaio FJ, Glina S: Epidemiologic study on penile cancer in Brazil. Int Braz J Urol. 2008; 34: 587-91; discussion 591-3.

5. Heyns CF, Mendoza-Valdés A, Pompeo AC: Diagnosis and staging of penile cancer. Urology. 2010; 76: S15-23.

6. Pompeo AC: Extended lymphadenectomy in penile cancer. Can J Urol. 2005; 12 (Suppl 1): 30-6; discussion 97-8.
7. Pompeo AC, Heins CF, Abrams P: International Consultation on Urological Diseases- Penile Cancer. Montreal, Société Internationale d'Urologie. 2009; vol. 1.

8. Tobias-Machado M, Tavares A, Molina WR Jr, Forseto PH Jr, Juliano RV, Wroclawski ER: Video endoscopic inguinal lymphadenectomy (VEIL): minimally invasive resection of inguinal lymph nodes. Int Braz J Urol. 2006; 32: 316-21.

9. Sotelo R, Sánchez-Salas R, Carmona 0, Garcia A, Mariano M, Neiva G, et al.: Endoscopic lymphadenectomy for penile carcinoma. J Endourol. 2007; 21: 364-7; discussion 367.

10. Herrel LA, Butterworth RM, Jafri SM, Ying C, Delman KA, Kooby DA, et al.: Bilateral endoscopic inguinofemoral lymphadenectomy using simultaneous carbon dioxide insufflation: an initial report of a novel approach. Can J Urol. 2012; 19: 6306-9.

\author{
Correspondence address: \\ Dr. Fernando Kim \\ Chief of Urology, Denver Health Medical Center \\ 777 Bannock St, MC 0206 \\ Denver, CO 80204 \\ Telephone: + 1303 436-6558 \\ E-mail: fernando.kim@dhha.org
}




\section{EDITORIAL COMIMENT}

Penile cancer should be a great point of interest in public health systems in developed and developing countries. The surgery with the objective to cure this illness always causes some degree of mutilation and morbidity. Conventional open bilateral lymphadenectomy is the gold standard access for suspected or macroscopically positive nodes (1). With the intention to minimize morbidity, days in hospital and, at last, costs, the use of video endoscopic inguinal lymphadenectomy (VEIL) is feasible and should be encouraged. In this interesting paper the authors bring us some skills and a complete reproducible technique for the VEIL access. As mentioned in the text, it is not the first time that the simultaneous bilateral access is performed (2). Maybe in the future the bilateral VEIL is going to be the standard access in high skilled centers. The authors have a great experience in this technique, certainly soon we will have more papers with a greater number of cases and follow-up.

\section{REFERENCES}

1. Protzel C, Alcaraz A, Horenblas S, Pizzocaro G, Zlotta A, Hakenberg OW: Lymphadenectomy in the surgical management of penile cancer. Eur Urol. 2009; 55: 1075-88.

2. Herrel LA, Butterworth RM, Jafri SM, Ying C, Delman KA, Kooby DA, et al.: Bilateral endoscopic inguinofemoral lymphadenectomy using simultaneous carbon dioxide insufflation: an initial report of a novel approach. Can J Urol. 2012; 19: 6306-9. 